University of Nebraska - Lincoln

DigitalCommons@University of Nebraska - Lincoln

Nutrition and Health Sciences -- Faculty

Publications

Nutrition and Health Sciences, Department of

8-2006

\title{
Using Initiative to Achieve Autonomy: A Model for Advanced Practice in Medical Nutrition Therapy
}

Annalynn Skipper

Annalynn Skipper and Associates, Oak Park, IL

Nancy M. Lewis

University of Nebraska--Lincoln, nlewis2@unl.edu

Follow this and additional works at: https://digitalcommons.unl.edu/nutritionfacpub

Part of the Dietetics and Clinical Nutrition Commons

Skipper, Annalynn and Lewis, Nancy M., "Using Initiative to Achieve Autonomy: A Model for Advanced Practice in Medical Nutrition Therapy" (2006). Nutrition and Health Sciences -- Faculty Publications. 13. https://digitalcommons.unl.edu/nutritionfacpub/13

This Article is brought to you for free and open access by the Nutrition and Health Sciences, Department of at DigitalCommons@University of Nebraska - Lincoln. It has been accepted for inclusion in Nutrition and Health Sciences -- Faculty Publications by an authorized administrator of DigitalCommons@University of Nebraska - Lincoln. 


\title{
Using Initiative to Achieve Autonomy: A Model for Advanced Practice in Medical Nutrition Therapy
}

\author{
Annalynn Skipper PhD, RD, Annalynn Skipper and Associates, PO Box 45, Oak Park, IL 60303
}

Nancy M. Lewis PhD, RD, Department of Nutrition and Health Sciences, University of Nebraska-Lincoln

\begin{abstract}
The purpose of this research was to generate a model of advanced medical nutrition therapy (MNT) practice based on descriptions of their clinical activities provided by advanced-level MNT practitioners. A qualitative approach using grounded theory methodology was employed. The model of advanced MNT practice was based on interviews with 21 credentialed advanced practice registered dietitians from across the United States and Canada. Verbatim transcripts of the interviews were coded for aggregation into themes and subthemes. The resulting model included a single overarching theme: using initiative to achieve autonomy. The five subthemes are aptitude, attitude, expertise, context, and approach. The model provides a richer picture of advanced MNT practice than was previously available and is presented for discussion and debate. Validation of the model is required before incorporation into education or practice.
\end{abstract}

$\mathbf{M}$ any registered dietitians (RDs) practicing medical nutrition therapy (MNT) are recognized informally for advanced knowledge and highly skilled practice, but experience difficulty in formally differentiating their expertise from that of basic-level practitioners. Advanced dietetic practitioners are described as having a master's degree; a minimum of 8 years' experience; multiple professional role positions with complex and diverse responsibilities and functions; a diverse network of broad, geographically dispersed professional contacts; and an innovative, creative, and intuitive approach to practice that reflects a global perspective (1). Others have based advanced practice on years of experience or promotion to a management role (2-4). However, practitioner characteristics alone present an incomplete picture of advanced MNT practice because they do not describe what advanced practitioners do.

In contrast, nurses have defined practitioner characteristics and the tasks that advanced practice nurses do. The distinction between basic and advanced-level nursing practice supports acquisition of additional skills and a ca- reer ladder (5-7). Nurses have measured positive outcomes achieved by advanced-level practitioners (8). Advanced practice nursing positions have been developed and salary increases have accompanied these positions (7).

It is possible that advanced practice skills and a career ladder in dietetics could benefit RDs and, ultimately, their patients. A description of advanced MNT practice would serve as a basis for research into the characteristics of an advanced practice role. This research was designed to generate a model of advanced MNT practice based on descriptions of clinical activities as provided by advanced-level MNT practitioners.

\section{Methods}

A qualitative research method, grounded theory, was selected because it is an effective research method for describing emerging or previously undescribed phenomenon $(9,10)$. Grounded theory is based on analysis of in-depth interviews with informants knowledgeable about the phenomenon or process being studied. For this study, interviews were conducted by a trained interviewer according to a semistructured interview guide. During the interviews, participants were asked to describe advanced practice and to explain the difference between advanced- and basic-level practices. A draft advanced practice model was developed based on the available literature and compared with entry-level dietetic education standards to ensure that it did not overlap $(1,5-8,11-17)$. Interviewees were given a copy of the draft model for review and comment.

Purposeful sampling (10) was used to identify RDs in MNT practice who (a) possessed an advanced practice credential in dietetics [fellow of the American Dietetic Association or Board Certified Advanced Diabetes Manager $(18,19)]$, or $(b)$ had published or conducted research on advanced practice topics. Interviews were conducted by a single individual, according to the method of Kvale (20), from February through August of 2004. The research protocol was approved by the Institutional Review Board of the sponsoring institution and informed consent was obtained. 
Atlas.ti software (Version 5.0, 2004, Thomas Muhr Scientific Software Development, Berlin, Germany) was used to code interview transcripts. Consistent coding was achieved with a subset of the data coded 10 weeks apart. Additional validation was accomplished with triangulation, which was defined as prolonged contact with the data. Member checking in which the final model was sent to study participants to ensure that their views were accurately reflected was also used (21). Substantive or open codes were collapsed into theoretical codes to generate the model (22).

\section{Results}

Twenty-one RDs from 14 states and Canada were interviewed. Interviews lasted from 25 to 105 minutes and resulted in a 304-page transcript. The majority of interviewees worked in community hospitals, but long-term care, outpatient clinic, homecare, private and joint physician practice, government health care, academic medical centers, and clinical research settings were represented. RDs with expertise in pediatrics, renal, diabetes, and nutrition support were included. Three also held credentials in medicine or nursing.

The result of the study is the model in Figure 1. The overarching theme was "using initiative to achieve autonomy." Five subthemes - aptitude, attitude, context, expertise, and approach-emerged. A definition of initiative that seems to describe the interviewees is "at one's own discretion; independently of outside influence or control" (23). Initiative surfaced in several ways. One interviewee developed mechanisms to improve patient care, stating "not hurting the patient isn't enough - my job is to help make things better for the patient." Another initiated interventions for her clients stating "it was wrong to practice in a receptive way, waiting to be told what to do." Interviewees maintained both career and work agendas, and saw themselves as directing those agendas. One sought increasingly challenging positions in her successful quest to earn a six-figure salary within 10 years of graduation. Another perceived herself and other advanced practice RDs as shaping and defining their own career ladders, rather than merely climbing a career ladder determined by someone else.

Autonomy, defined by Webster as "the quality or state of being self governing," was often a result of initiative (23). Most interviewees had moved beyond traditional roles and structures. Movement from a traditional role, job, or department was often cited as a prerequisite to advanced practice. One RD successfully convinced a nationally known physician to hire her rather than a nurse to manage a new clinic. Another changed departments to facilitate initiatives that were "too scary" for the dietary department in her hospital. Others moved into private practice or joint practice within a physician group to achieve autonomy. One RD established a new department within her hospital. Another stated emphatically: "there was no one behind us pushing; we led our practice."

One RD was so strongly committed to autonomy that she declined referrals from a prominent physician who dictated the therapy provided to his patients. Another obtained advanced practice nursing credentials because she "did not want to be a puppet." A third RD reflected on her decision to obtain a physician assistant credential, stating "I wanted to be able to continue to manage patients independently. So it was really more autonomy and to know more about medicine."

The most frequently cited example of autonomous practice was the ability to independently order, modify, and monitor MNT. Several RDs had obtained clinical privileges to order parenteral and enteral nutrition, diets and laboratory tests, or modify medications such as insulin, phosphate binders, and calcium and iron supplements. Interviewees mentioned the additional responsibility associated with autonomous practice, but found it a satisfying means to provide better care.

\section{Aptitude}

The aptitude subtheme was composed of education, experience, and credentials. Interviewees uniformly expressed the need for graduate-level education as a prerequisite to advanced practice. According to one RD:

"I think that just on a personal level it became very obvious to me that my internship, which was excellent, and my undergraduate work did not prepare me to do things ... I knew how much I didn't know. ... I can't provide a really good service because I don't know enough. So that is why I went to graduate school."

Interviewees were more positive about their own graduate education when curricula related to clinical practice. There was little enthusiasm for the traditional normal nutrition- and biochemistry-based graduate curriculum. There was uniform support for the practice doctorate degree because it represented advanced education in clinical practice. The value of an original research project was recognized, but the need for practice-based research opportunities was often mentioned.

RDs expressed the need for a minimum of 5 to 7 years of experience after obtaining the RD credential as necessary for advanced practice. One participant described herself as "still fresh" after 10 years of practice. Other credentials, including certification, publications, presentations, volunteer leadership positions, and program development were mentioned as prerequisite to advanced practice. There was uniform agreement that education alone, even at the practice doctorate or PhD level, was insufficient for advanced practice and that several years of experience in addition to that obtained through formal education were needed.

\section{Attitude}

The attitude subtheme is characterized by a breadth and balance of perspective, scientific inquiry, and creativity. The necessity of a broad perspective was expressed at the professional level as "connecting with other people's sciences and languages in order to provide a total treatment approach." At the patient level, breadth of perspective included understanding the "whole picture," not just the nutritional issues.

Scientific inquiry was expressed on two levels, one related to the scientific literature and another related to patient 


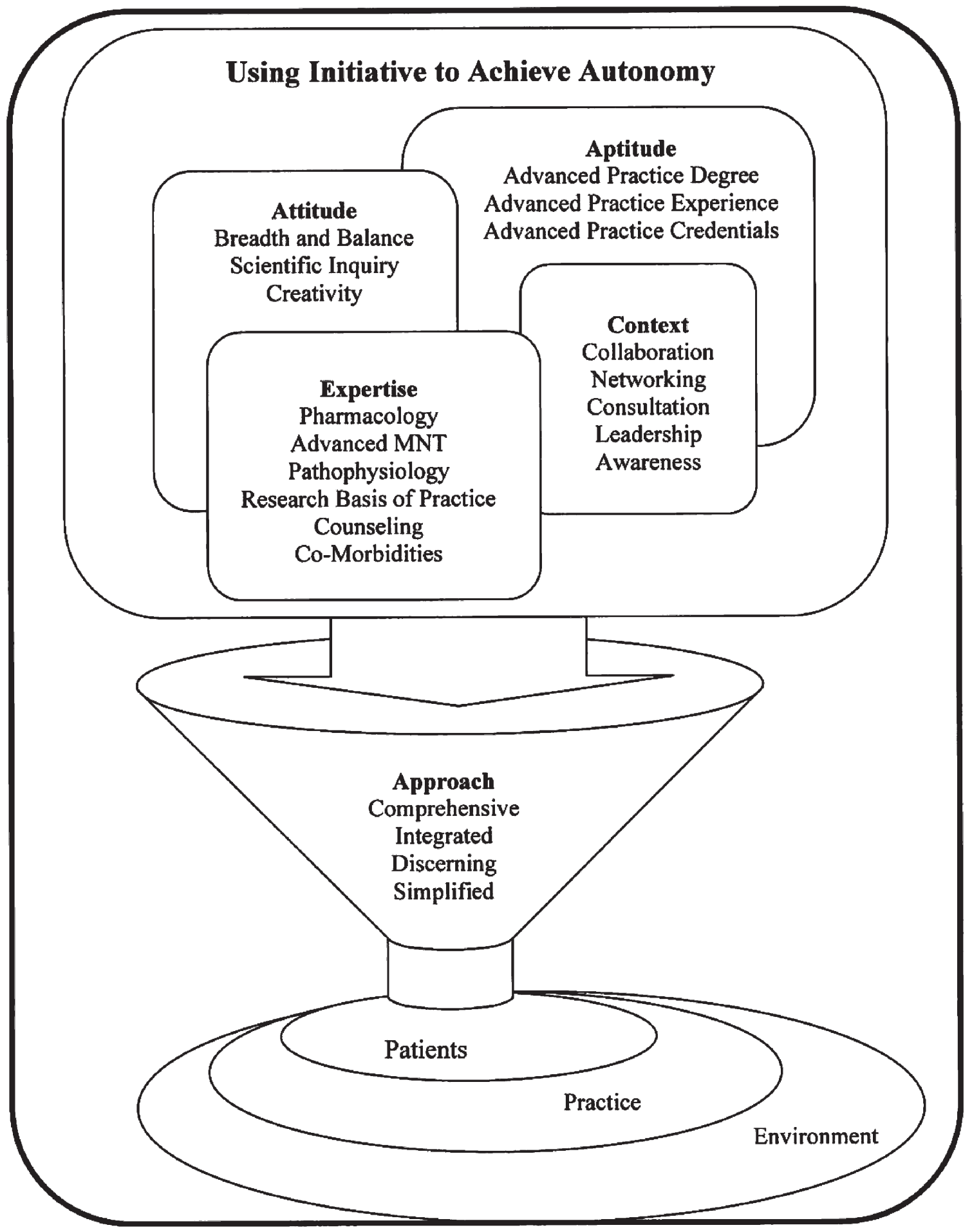

Figure 1. Using initiative to achieve autonomy: A model of advanced medical nutrition therapy (MNT) practice.

care. Interviewees voiced the need for an evidence-based approach and had developed the ability to critically read and apply research findings specific to their patient population. With patients, these advanced practice RDs looked beyond the obvious information to understand situations that did not go as planned. One mentioned the ability to delve deeper into a situation, the ability to ask: "what is going on, what's really happening here?"
Creativity was used to innovate and to survive. Interviewees stimulated their creativity with knowledge from other areas of dietetics, and from education, psychology, information science, medicine, or business. One suggested "once you get all these different ideas you can integrate them, and try to come up with creative solutions." More than one mentioned leaving jobs when creativity was no longer possible. 


\section{Context}

The context subtheme refers to the relationship of advanced practitioners to their environment. Components of context include collaboration, networking, consultation, leadership, and awareness. Collaboration was expressed as the need to be connected through teamwork and networks with other individuals. Understanding the role and perspective of nurses, physicians, pharmacists, and others involved in patient care was considered essential. Multidisciplinary teams were regarded as a patient care enhancement, as were teams of colleagues within and outside the work setting. Collaborative activities included being "where the decisions are made" at patient care rounds, as well as interdisciplinary and cross-departmental meetings.

These RDs valued networks with other RDs, maintaining extensive groups of colleagues with whom they exchanged information or developed intellectual partnerships. They sought and provided mentorship to and from these networks and benefited from mentors outside the profession as well. A number mentioned strong physician mentors, but mentors from other disciplines were also acknowledged.

A component of collaboration is the consultation and referral process, traditionally used by physicians to seek and provide advice concerning complex cases. Interviewees expressed comfort in using the physician model for consultation. They had established referral networks, and were confident that their recommendations were valued. They derived satisfaction from seeking or providing consultation with other RDs on difficult cases, or being asked to share expertise through teaching.

All interviewees had been invited speakers and authors. However, these leadership activities were mentioned in an offhand way, almost as an afterthought. Leadership was more often defined as the ability to make a contribution or a difference. One described being invited to a foreign country to change practice as an example of leadership. For another, leadership was contacting officers of a national professional organization to facilitate a response to a federal agency. Others mentioned involvement with policy issues within professional organizations and government. All cited examples of participating as change agents.

These RDs expressed awareness of the political, economic, and regulatory influences in their environment. They challenged administrative structures or created their own as needed, but exhibited finely developed political skills, which were used to obtain cooperation and support for their initiatives. One advised to "evaluate the system and its effectiveness and enter into the system as you need to." They actively pursued both a professional and work agenda against sometimes overwhelming odds. However, awareness was expressed as "sometimes you can't change things because you don't have control..., but at least you share the information and work with your group toward that end."

\section{Expertise}

MNT practitioners demonstrated specialty expertise. They easily discussed complex therapy and difficult patients, spontaneously giving rich examples of sophisticated interventions. One interviewee noticed that advanced practice
RDs have "a vaster knowledge as far as pharmacotherapy." Diabetes and nutrition support RDs manipulated insulin; renal RDs often managed drug protocols that impacted iron, calcium, and phosphorus metabolism. Thus, pharmacology was the most often mentioned area of advanced practice expertise. Rather than the single approach used by the basic level practitioner, these RDs depended on their experience and knowledge to select from a wide variety of MNT interventions based on individual patient needs.

There was a great deal of interest in advanced nutrition pathophysiology as a basis for MNT for disease management and prevention of comorbidities. Interviewees could discuss aberrations in nutrient metabolism related to specific diseases, but traditional biochemistry was rarely mentioned. One interviewee described advanced practice as "not only to be up-to-date on the reading, but to participate in research in some way or another." Another stated:

"When they come with that complex problem, you don't stop and think well, how will I know? They talk to you and you can just start quoting the literature and you can talk to them about what's going on and you can look at the patient and help figure something out. Maybe you can't fix it, but you realize where your limitations are and where your potential is."

Counseling expertise was deemed important by those whose practice required it. The application of counseling skills included selecting among models to best meet the needs of the patient. Practitioners were conscious of their unique contribution in identifying and preventing nutrition-related comorbidities in their patients. Their knowledge of nutrition- and nonnutrition-related comorbidities was viewed as necessary to treat the whole patient.

\section{Approach}

The approach used by the interviewees was applied to patients, to practice, or to other areas including the practice environment. It was comprehensive, integrated, yet discerning and simplified. One example of a comprehensive approach was described by an interviewee who examined patient information in terms of what was to be done with it while considering its theoretical background. Interviewees were skilled in "picking up things that others might not have taken time to identify" or "seeing things that a basic level dietitian just doesn't see."

Advanced practitioners also integrated information, and described thinking in terms of relationships and patterns that enabled them to streamline activities, increasing productivity and effectiveness. The need to integrate therapy within the overall treatment plan was frequently mentioned. One example was:

\footnotetext{
"An advanced practice RD in diabetes is looking at overall clinical management. Not just the MNT piece. And you're looking at integrated therapy, and integrating therapy, so by that I would define it as the MNT piece, physical activity, having the strong knowledge base of oral diabetes medication. The various insulin regimens, the types of insulin. So understanding how that all works together with the diabetes management and not just paying attention to the glucose control but also to blood pressure and lipids."
} 
Interviewees understood the whole treatment plan, knowing when nutrition was a primary concern and when other issues took precedence. These RDs were very comfortable participating as full-fledged, valued members of the medical team, exhibiting a sense of entitlement to provide nutrition and associated care.

Discernment was used to individualize activities based on need. For example, one interviewee mentioned that she did not have time to conduct a physical assessment on every patient, but did them "as needed, according to criteria I have in my head." For another, discernment was a difference in advanced and basic level practice, with advanced practitioners able to easily target the most important issues.

"So now I do a brief look at this baby outside the room, and based on what I know I want. I know what question to ask because I'm looking for specific information. I'm targeting, I'm going in to find out the specific information to support or to complete my initial assessment. Because I've got 10 minutes with them. I'm not sure you would do that if you didn't have some experience. I have a colleague ... who hasn't been able to define and hone in on what is important and what is not. She still has to get every detail. She has this fear that she will miss something. And in some instances I would perform like my colleague. And in another instance I would not perform that way, and I guess I'm discerning which place to use it."

A further elaboration of the approach to practice included the ease with which interviewees served as both conduit and crucible, distilling complex information to simplicity as necessary. These practitioners presented an uncomplicated approach by targeting key issues and discarding superfluous information. According to one:

"The advanced practitioner makes it look simple. ... goes in and looks at all that's around to come up with a summation. And it looks simple to the outsider, but that's where the novice doesn't realize the training and all the background that it took to get to that point. To synthesize complex information and to make it simplified in order to apply it to clinical practice."

Interviewees focused on "the heart of the matter," succinctly summarized nutritional issues at the highest professional level, then instantly and clearly explained the same issue to patients, family members, or those with little framework for understanding.

Because most interviewees were involved in direct patient care, the most frequent examples of application of the elements in the model were related to patient care; however, as illustrated in the concentric circles at the bottom of the model, advanced practice RDs impact more than individual patients. In approaching patients, interviewees frequently synthesized and applied new information but avoided concepts that were irrelevant or unworkable. In reference to the work environment, one RD described her approach to new information saying "just because it's new, doesn't mean it's the best thing out there. Sometimes it's a marketing issue," then described developing protocols to manage nutrient-drug interactions in a dialysis unit.

These RDs were influential in the larger environment, serving on interdepartmental committees or participating in policy initiatives within professional organizations. One interviewee mentioned mobilizing her professional orga- nization to intervene in evolving government regulations. Several mentioned participating in research projects based on clinical practice questions or collection and aggregation of outcomes data where the results were shared in professional journals or at national meetings.

\section{Discussion}

Study results are presented in the form of a model of advanced practice as described by advanced practice RDs (Figure 1). The intent was to provide information about what advanced practice RDs do rather than who they are. The overarching theme "using initiative to achieve autonomy," provides some insight into what practitioners do. Most advanced practice RDs interviewed for this study exhibited all of the characteristics depicted in this model, suggesting that it should be viewed as a whole. This is especially true of the advanced practice degree, experience, and credentialing portions of the model, all of which were considered by the interviewees as prerequisites for advanced practice.

The stages of professional development from novice to expert were first articulated by Dreyfus and Dreyfus in a study of pilots (24). Chambers and colleagues applied these stages in an article on competency-based education in dietetics (25). The model derived during the present study is based on the language of the study participants; thus, the terminology used is unique to the model. However, the performer responsibility, integration of procedures, and interdependence characteristics described by Chambers and colleagues could be analogous to the autonomy, integration, and collaboration components of the model (25).

Characteristics of advanced-level practitioners in the present sample are similar to those identified by Bradley and colleagues (1). However, these investigators did not describe the importance of autonomy or the ease with which advanced-level practitioners constantly processed, reformatted, and added to the depth and breadth of expertise needed for their practice. Interviewees applied this approach to scientific and medical literature, patient data, practice guidelines, and psychosocial information, as shown in the portion of the model labeled patients, practice, and environment in Figure 1. More importantly, they were aware of the context of the information and the theory supporting it, which was not articulated by Bradley and colleagues (1).

RDs practicing according to the model in Figure 1 might impact existing practice including documents that influence practice. For example, the advanced practice RD would select from available nutrition care processes based on desired outcome, but would influence environmental factors rather than respond to them as the Nutrition Care Process model suggests $(26,27)$. Many of the tasks identified as advanced in the Standards of Practice and Standards of Professional Performance for Registered Dietitians (generalist, specialty, and advanced) in diabetes care and also behavioral health are consistent with the model $(28,29)$.

An inconsistency between the model and the American Dietetic Association's recently revised definition of advanced practice exists. The definition states that practice characteristics are "shaped by the context in which an RD practices" $(28,30)$. However, these findings suggest that the advanced practice RD shapes the practice context rath- 
er than as described in the existing definition. If the model is validated, a change in this wording might be considered.

Qualitative methodology is considered a limitation by some educated in the quantitative tradition. Quantitative research is preferred, but several of the National Institutes of Health have funded grounded theory research projects. This suggests a trend toward using qualitative methods when quantitative methods cannot be used (31). In dietetics and nutrition, grounded theory has been used to describe interactions and roles in dietetics and as a basis for better understanding of food insecurity and menu development (32-34).

Another limitation of the study might be the purposeful sampling strategy in which practitioner criteria were used to identify study participants. It is unknown if there are advanced-level practitioners who do not meet the practitioner criteria used to select study participants. It is also possible that educational programs, mentoring projects, residencies, or fellowships prepare advanced-level practitioners, but a comprehensive listing of such programs is not readily available.

\section{Conclusions}

The model developed from this study and the practitioner comments provide a clearer description of advanced MNT practice. It is presented for discussion and debate.

If validated, the model could be used by RDs, educators, and employers as a benchmark to assess advanced practice competency. Employers could use the model to develop appropriate positions and salary structures for advanced MNT practice. The model will have implications for educators designing advanced-level MNT education programs.

Additional topics for study include the use of the model to differentiate levels of MNT practice, design of educational programs jointly sponsored by academic institutions to prepare RDs for advanced practice, the need for the advanced practice doctorate and advanced practice RDs, and the impact of advanced-level practitioners on patient outcome.

Acknowledgments - This manuscript is a contribution of the University of Nebraska Agricultural Research Division, Lincoln, NE 68583, Research Bulletin No. 14991. This research was supported in part through the Hatch Act.

\section{References}

1 R. T. Bradley, W. Y. Young, P. Ebbs, and J. Martin, Characteristics of advanced-level dietetics practice: A model and empirical results, J Am Diet Assoc 93 (1993), pp. 196-202.

2 M. T. Kane, A. S. Cohen, E. R. Smith, C. Lewis, and C. Reidy, 1995 Commission on Dietetic Registration dietetics practice audit, J Am Diet Assoc 96 (1996), pp. 1292-1301.

3 D. Rodgers, B. L. Leonberg, and C. B. Broadhurst, 2000 Commission on Dietetic Registration: Dietetics practice audit, J Am Diet Assoc 102 (2002), pp. 270-292.
4 Nutrition Support Dietitian Role Delineation Survey: Supplemental Report, National Board of Nutrition Support Certification, Inc, Silver Spring, MD (1997) Anonymous.

5 S. J. Brown, A framework for advanced practice nursing, J Prof Nurs 14 (1998), pp. 157-164.

6 J. D. Calkin, A model for advanced nursing practice, J Nurs Admin 14 (1984), pp. 24-30.

7 A. Skipper, The history and development of advanced practice nursing: Lessons for dietetics, J Am Diet Assoc 104 (2004), pp. 1007-1012.

8 M. O. Mundinger, R. L. Kane, E. R. Lenz, and A. M. Totten, Primary care outcomes in patients treated by nurse practitioners or physicians: A randomized trial, JAMA 283 (2000), pp. 59-68.

9 B. Glasner and A. Strauss, The Discovery of Grounded Theory: Strategies for Qualitative Research, Aldine, Chicago, IL (1967).

10 J. W. Creswell, Qualitative Inquiry and Research Design: Choosing among the Five Traditions, Sage, Thousand Oaks, CA (1998).

11 B. W. Christie and M. A. Kight, Educational empowerment of the clinical dietitian: A proposed practice doctorate curriculum, J Am Diet Assoc 93 (1993), pp. 173-176.

12 R. Touger-Decker, Advanced-level practice degree options: Practice doctorates in dietetics, J Am Diet Assoc 104 (2004), pp. 1456-1458.

13 A. Skipper and N. M. Lewis, A look at the educational preparation of the health diagnosing and treating professions: Do dietitians measure up?, J Am Diet Assoc 105 (2005), pp. 420-426.

14 P. A. Benner, From Novice to Expert: Excellence and Power in Clinical Nursing Practice, Addison-Wesley, Menlo Park, CA (1984).

$15 \mathrm{M}$. V. Fenton, Identifying competencies of clinical nurse specialists, J Nurs Admin 15 (1985), pp. 31-37.

16 In: A. B. Hamric, J. A. Spross, and C. M. Hanson, Editors, Advanced Nursing Practice (2nd ed.), WB Saunders, Philadelphia, PA (2000).

17 K. S. Bruening, B. E. Mitchell, and M. M. Pfeiffer, 2002 accreditation standards for dietetics education, J Am Diet Assoc 102 (2002), pp. 566-577.

18 R. T. Bradley, Fellow of the American Dietetic Association credentialing program: Development and implementation of a portfolio-based assessment, J Am Diet Assoc 96 (1996), pp. 513-517.

19 A. Daly, K. Kulkarni, and J. Boucher, The new credential: Advanced diabetes management, J Am Diet Assoc 101 (2001), pp. 940-943.

20 S. Kvale, InterViews, Sage, Thousand Oaks, CA (1996).

21 R. Chiovitti and N. Piran, Rigour and grounded theory research, J Adv Nurs 44 (2003), pp. 427-435.

22 B. Glaser, Emergence vs Forcing: Basics of Grounded Theory Analysis, Sociology Press, Mill Valley, CA (1992).

23 Merriam-Webster Online (2004); http://www.m-w.com (accessed March 19, 2005).

24 H. L. Dreyfus and S. E. Dreyfus, Mind Over Machine: The Power of Human Intuitive Expertise in the Era of the Computer, NY Free Press, New York, NY (1986). 
25 D. W. Chambers, C. J. Gilmore, J. O. Maillet, and B. E. Mitchell, Another look at competency based education in dietetics, J Am Diet Assoc 96 (1996), pp. 614-617.

26 K. Lacey and E. Pritchett, Nutrition Care Process and Model: ADA adopts road map to quality care and outcomes management, J Am Diet Assoc 103 (2003), pp. 1061-1071.

27 N. Hakel-Smith and N. M. Lewis, A standardized nutrition care process and language are essential components of a conceptual model to guide and document nutrition care and patient outcomes, J Am Diet Assoc 104 (2004), pp. 1878-1884.

28 K. Kulkarni, J. Boucher, A. Daly, C. Schwide-Slavin, B. Silvers, J. O'Sullivan Maillet, and E. Pritchett, American Dietetic Association: Standards of Practice and Standards of Professional Performance for Registered Dietitians (generalist, specialty, and advanced) in diabetes care, J Am Diet Assoc 105 (2005), pp. 819e-824e.

29 M. Emerson, P. Kerr, M. D. C. Soler, T. Girard, R. Hoffinger, E. Pritchett, and M. Otto, American Dietetic Association: Standards of Practice and Standards of Professional Performance for Registered Dietitians (generalist, specialty and advanced) in behavioral health care, $J$ Am Diet Assoc 106 (2006), pp. 608e-613e.
30 American Dietetic Association. Scope of Dietetics Practice Framework: Decision Aids: Definition of Terms. Practice Framework Documents; http://www.eatright. org/ada/files/Section4BTerms.pdf (accessed February 22, 2005).

31 Computer Retrieval of Information on Scientific Projects. http://www.crisp.cit.nih.gov. Available at: Accessed April 10, 2006.

32 C. M. Devine, M. Jastran, and C. Bisogni, On the front line: Practice satisfactions and challenges experienced by dietetics and nutrition professionals working in community settings in New York State, J Am Diet Assoc 104 (2004), pp. 787-792.

33 M. E. Briley, C. Roberts-Gray, and D. Simpson, Identification of factors that influence the menu at child care centers: A grounded theory approach, J Am Diet Assoc 94 (1994), pp. 276-281.

34 W. S. Wolfe, E. A. Frongillo, and P. Valois, Understanding the experience of food insecurity by elders suggests ways to improve its measurement, J Nutr 133 (2003), pp. 2762-2769. 